This is the final peer-reviewed accepted manuscript of:

Mulazzani, Luca; Camanzi, Luca; Bonezzi, Alfonso; Malorgio, Giulio

Individual transferable effort quotas for Italian fisheries? A preliminary analysis

which has been published in final form in Marine policy Volume 91, May 2018, Pages

$14-21$

The final published version is available online at:

https://doi.org/10.1016/i.marpol.2018.01.033

(C) 2018 Elsevier. This manuscript version is made available under the Creative Commons Attribution-NonCommercial-NoDerivs (CC BY-NC-ND) 4.0 International License (http://creativecommons.org/licenses/by-nc-nd/4.0/) 


\section{Individual transferable effort quotas for Italian fisheries? A}

2 preliminary analysis

3

4

5

6

\section{(}

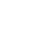

\section{Abstract}

In the context of transferable fishing concessions, the most well-known tool is probably the individual transferable quota, whereas the case of individual transferable effort quotas (ITEs) is much less often discussed. This study is the result of a project realized in collaboration with Italian fishery associations with the objective of valuating, in a participatory framework, the possible consequences of the introduction of ITEs. A semi-quantitative survey was carried out over a sample of key stakeholders being experts of bottom trawling fisheries in the Tyrrhenian and Adriatic Seas and the pelagic trawling fishery in the Adriatic Sea. The results and elaborations of the surveys were discussed and validated by a focus group composed of delegates of fishery associations. Two aspects were investigated: the relationships between fishing capacity (i.e. engine power and gross tonnage), fishing activity (i.e. fishing days and fishing hours), revenues, and variable costs (e.g. fuel) and the suitability of different proposals and alternative approaches for the introduction of ITEs. The participation of stakeholders allowed the building of some simple pedagogical tools based on realistic figures collected through the surveys that could be used by managers of associations, cooperatives, and producer organizations to better understand the functioning and possible consequences of ITEs schemes.

Keywords: transferable fishing concessions; participative management; transferable effort quotas; Mediterranean; fishers' behaviour.

\section{Introduction}

Regulation (EU) No 1380/2013 of the European Parliament and of the Council on the Common Fisheries Policy introduces the concept of 'transferable 
32 fishing concessions' (TFCs) as a revocable user entitlement to specific fishing opportunities. This scheme is included in the regulation as a voluntary approach for Member States. Importantly, in the first version of the regulation prepared by the European Commission in 2011, TFCs were mandatory for all vessels longer than $12 \mathrm{~m}$. This strategy was considered optimal in order to adjust the overcapacity of EU fleets and increase fishery efficiency, but criticisms from several sources, including the Regional Advisory Council for the Mediterranean and the Italian Senate, led to a softer, voluntary regulation.

However, TFCs remain a recurring theme in EU policy debates, and it is important for stakeholders to better understand their application and possible consequences in order to take an objective position. In the framework of TFCs, the most well-known tools are probably individual transferable quotas (ITQs), whereas the case of individual transferable effort quotas (ITEs) is much less discussed (MRAG et al., 2009; OECD, 2006; Squires et al., 2016, 2012). ITEs were mentioned by the European Commission in their preliminary documents on fishery policy reform, and, more precisely, they were associated with the Mediterranean case, where management is already driven by fishing effort regulation ${ }^{1}$ and where multispecificity may represent an obstacle for ITQs, inducing overquota discards (Baudron et al., 2010; Ulrich et al., 2002). Furthermore, ITEs provide automatic feedback control (i.e. catch changes) when fish stocks increase or decrease, which may be more effective than ITQs at managing fishing mortality when there is a high unpredictable annual recruitment variation and short-lived species, which is the case for several Mediterranean stocks, and when biomass data is of low availability or quality (Squires et al., 2016).

The introduction of TFCs (or market-like instruments, as the OECD calls them) is often met with resistance from participants in the fisheries sector. For this reason, the OECD (2006), based on several experiences, presented a list of tracks that policy makers can draw upon in meeting these challenges and

1

Total allowable catches are not generally used in Mediterranean fisheries, with an exception made for tuna (Thunnus thynnus). 
62 that can ease the introduction and improve the design of these instruments.

63 The first of these tracks is 'making all stakeholders comfortable with the 64 concept of market-like instruments', followed by others, such as 'preferring an incremental or gradual implementation', 'not necessarily adopting a onesize-fits-all strategy', and 'involving stakeholders in the reform process' (OECD, 2006).

In this framework, this study is the result of a project realized for the Italian Ministry of Agriculture, with the active participation of three Italian fishery associations (Agci Agrital, Federcoopesca-Confcooperative, and Lega PescaLegacoop) ${ }^{2}$ joined in the 'Alliance of Italian Cooperatives', with the objective of valuating the possible consequences of the introduction of ITEs. These three associations combined represent more than 1500 cooperatives involved in fisheries or aquaculture with more than 20,000 members who are responsible for about $80 \%$ of Italian fish production. It is very important that stakeholder associations, with the collaboration of research institutions, lead similar initiatives, fostering the participation of fishers and the dissemination of results. The main objective of the project, and the paper, is to build, through a participative approach, a few pedagogical tools that can be used by fishers' associations to evaluate the possible effects of the introduction of ITEs.

This paper follows the approach used in the project and is organized as follows. In the next chapter, we consider how ITEs have been applied in other contexts. In chapter three, we present the methodological approach used for the study. In chapter four, we illustrate the results, including the models generated from focus groups with stakeholders. Chapter five concludes the paper. Two appendices are included in order to illustrate, more formally and with simulations, some bioeconomic aspects linked to the introduction of ITEs; these tools were useful to prepare the questionnaire and the discussion with the fishery associations' delegates.

2

Administratively, this project was led by Federcoopesca-Confcooperative. 


\section{Background}

Management schemes based on transferable fishing concessions, property rights, or market-like instruments generally assume that private forces, spontaneously, may drive economies toward maximum efficiency. The OECD and FAO (OECD, 2006) agree that these instruments have to be considered as 'use rights' rather than property rights. In this context, ITQs are the tools that are more studied in the literature (they were analytically considered for the first time by Christy (1973)) and more applied to the management of fisheries (applications begun in the eighties (Breen et al., 2016)). ITEs, on the contrary, have been considered less frequently (Squires et al., 2016). In the appendices, we present an analytical framework for interpreting ITEs, whereas, in the following paragraphs, we discuss some applications, especially in European waters.

Squires et al. (2016, 2012) review several ITEs management approaches around the world. These approaches can be roughly classified into two groups: those where total allowable effort (TAE) is expressed as days at sea (which is closer to our interests), and those where it is expressed as the number of gears, such as pots, traps, or hooks.

Among days-at-sea schemes, the Faroe Islands demersal fishery is a wellknown example. In the mid-1990s, the Faroe Islands rejected the TAC system that was in place, especially due to extensive discarding when single-species quotas were filled, and substituted it with a TAE scheme consisting of ITEs (fishing days) for specific fleet categories (small trawlers, pair trawlers, longliners, and coastal fishing) (Baudron et al., 2010; Jákupsstovu et al., 2007). For example, due to catchability differences, one fishing day of a longliner <110 GT was equivalent to two fishing days using jigs. Since its introduction, the total number of fishing days allocated has been reduced several times, but these days have not been fully utilized, suggesting that the effort allocation is too high and is not able to reduce overcapacity and overfishing (Baudron et al., 2010; Jákupsstovu et al., 2007; Squires et al., 2012). 
124 Inside the European Union, the Netherlands and Denmark have applied

125 hybrid systems where ITEs (e.g. transferable kilowatt days) were 126 complementary tools to support ITQs, mainly to reduce the number of 127 fishing days and bycatches of overquota stocks (Andersen et al., 2010; MRAG 128 et al., 2009; OECD, 2006). More interesting and easy to analyse is probably the case of the Spanish ' 300 fleet', so called due to the number of Spanish vessels that the European Community allowed to fish in the Communitarian Atlantic EEZ when Spain entered into the Community (1986) (González Laxe, 2006; MRAG et al., 2009; OECD, 2006). In fact, only 150 'standard vessels' (of the 300) could fish simultaneously. The standard vessel was considered a vessel with a braking power of $700 \mathrm{hp}$, and conversion coefficients were defined for vessels with different powers. Conversion coefficients and braking power do not have a linear relationship, and, in fact, the coefficient changes less than proportionally compared with braking power, with an elasticity coefficient ${ }^{3}$ around 0.3 . After 1997, firms could exchange fishing day quotas, with a minimum and a maximum number of days that could be owned. In 2007, the TAE and ITEs scheme was substituted with a TAC and ITQs scheme.

The literature shows that in Spain, ITEs have been effective to reduce the size of the fleet (González Laxe, 2006; MRAG et al., 2009; OECD, 2006). However, the parameterization of 'standard vessels' on the basis of braking power has caused a decrease in average power and a contemporaneous increase in average gross tonnage (GT); at the same time, the spatial distribution of vessels has changed, fostering Galicia to the detriment of the Basque country.

Around the world, other ITEs schemes based on days at sea are found in New England ground fish fishery in the U.S., the Western and Central Pacific Ocean purse seine tuna fishery, and the Falkland Islands squid fishery 152 (Squires et al., 2016, 2012).

3

The elasticity coefficient is calculated as the percentage increase in the coefficient factor divided by the percentage increase in the braking power. 
153 Concerning Mediterranean countries, one study was carried out by Lucchetti 154 et al. (2014) to compare the strengths and weaknesses of different, possible 155 TFCs schemes, including ITQs and ITEs. Opinions were collected by several 156 public authorities. The conclusion of the study is that TFCs would not be 157 appropriate for the Mediterranean context (with the partial exception of

158

159 160

161

162

163

164 165

\section{Data and Methods}

\subsection{Study area}

The objective of this study is to evaluate the possible consequences of ITEs in Italian fisheries, involving stakeholders through a participative approach. This research has focused in particular on three Italian fisheries: the Adriatic pelagic trawling fishery, the Adriatic bottom trawling fishery, and the Tyrrhenian bottom trawling fishery. The Adriatic pelagic trawling fishery incudes 127 vessels (representing around 90\% of the Italian pelagic trawling fishery) with an annual production of around 41 million Euros (95\% of Italian production). The two bottom trawling fisheries (Adriatic and Tyrrhenian, excluding Sicily and Sardinia) include, respectively, 1,130 and 500 vessels (48\% and $21 \%$ of the Italian bottom trawling fishery), with an annual production of around 200 and 82 million Euros (48\% and 20\% of Italian production) (Mipaaf and NISEA, 2014).

In mid-2014, a Ministerial Decree introduced a new management scheme for the Adriatic fisheries (effective for both pelagic and bottom trawling) stating that, in order to reduce fishing efforts, each vessel had to choose either i) fishing five days per week for a maximum of 72 weekly hours or ii) fishing only four days per week ${ }^{4}$.

4

Fishing is always forbidden on Saturdays and Sundays in all sea areas. 


\subsection{Participatory management}

Fishers' participation in fisheries research and management is becoming more and more common despite the strong biological/positivistic tradition in fisheries management and the high level of government involvement. Without fishers' participation in research, the ability of fisheries managers is limited and new policy decisions can lead to low compliance and tension between stakeholders and authorities (Silver and Campbell, 2005). However, there is much uncertainty on how to best elicit stakeholders' information, objectives and options in a rigorous manner that support management decisions (Silver and Campbell, 2005).

For this scope, several qualitative or semi-quantitative approaches have been applied and can be found in fisheries literature. Martin-Smith et al. (2004) developed an ad hoc iterative process of consultation for the development of management options. Other tools are more focused on research questions rather than management objectives and include semistructured interviews (Trimble et al., 2014), participatory problem-solution trees (Manrique de Lara and Corral, 2017), excursions, seasonal calendars, historical timelines (Glaser et al., 2015), rapid rural appraisal techniques (Pido, 1995), experimental field games (Cleland, 2017), etc.

\subsection{Methodology}

For this study, a semi-quantitative approach has been used. Consultation with fishers occurred at two different points. First, at the beginning of 2016, a survey was conducted with 38 key stakeholders distributed in sixteen ports of eight Italian regions along the Adriatic and Tyrrhenian coasts (Figure 1). Key stakeholders were chosen by 'Alliance of Italian Cooperatives' experts mainly among vessel owners or captains that also have (or had) formal roles inside local cooperatives or producer organizations (normally, one or more cooperatives can be found in every port). In fact, the information collected is not directly related to the fishery activity of key stakeholders but on their own knowledge (as experts) of regional patterns. Second, the results and elaborations of the surveys were discussed and validated in a focus group composed of ten delegates of the fishery associations (Agci Agrital, 
215 Federcoopesca-Confcooperative, and Lega Pesca-Legacoop) at the regional 216 (six delegates for Tuscany, Apulia, Emilia-Romagna, Abruzzo, Calabria and 217 Sicily) and national (four delegates) level.

218 For the survey, eleven stakeholders (from three regions) were interviewed for the Adriatic pelagic fisheries; fifteen (from five regions) for the Adriatic bottom trawling fisheries, and twelve (from three regions) for the Tyrrhenian bottom trawling fisheries. These key stakeholders were consulted about their opinions on:

a) The relationships between fishing capacity (i.e. engine power and GT), fishing activity (i.e. fishing days and fishing hours), revenues, and variable costs (e.g. fuel) (for a formal treatment see appendix A).

b) The suitability of different proposals and alternative approaches for the introduction of ITEs.

The first part of the survey is important in order to understand the relationships among the variables normally used to estimate production functions, in particular how capacity affects activity, revenues, and variable costs (i.e. linearly or non-linearly) and how activity affects catches. These variables were measured by asking about the average daily revenue, daily variable cost, and yearly number of days at sea of an average vessel (given a certain GT and engine power) of a specific Italian region (the region of the person interviewed) using a specific gear (pelagic or bottom trawl). Regional reference values provided by official statistics (Mipaaf and NISEA, 2014) were communicated to the key stakeholders, and they could confirm or change them. Then, stakeholders were asked what difference in revenue, fuel cost, and days at sea should be expected for a vessel with a capacity (both GT and engine power) $20 \%$ larger and $20 \%$ smaller than the average vessel. The same procedure was followed to calculate the effect of yearly days at sea on yearly revenues.

These relationships are essential in order to understand which vessels (i.e. large or small) would take advantage of the introduction of ITEs. Other questions were related to the length of an average day at sea (for which no official data exist) and the reasons that a vessel spends fewer days at sea than would be theoretically allowable. 
248 In the second part of the survey, questions addressed the stakeholders' opinions about different aspects of ITEs, in particular:

a) The introduction of non-transferable quotas (or limits) of fishing days (in the case of the Adriatic Sea something similar was already introduced by the 2014 Ministerial Decree).

b) The use of weekly or monthly restrictions in the allowed fishing days.

c) Different patterns in the initial allocation of fishing days (Bellanger et al., 2016).

d) The introduction of transferability of fishing days.

e) Different approaches to permit the transferability of fishing days between vessels of different capacities (no constraints, transferability only within classes of vessels with similar capacity, or nominal effort quotas such as capacity*day).

The results and elaborations of the surveys were discussed and validated in a focus group composed of ten delegates of fishery associations at regional and national level. With the help of the delegates, starting from revenue and cost data, a generic tool to show the relationship between vessel capacity and daily value added was built for the bottom trawling fisheries. Finally, we built a simplified model indicating how the value added is distributed day by day. This model was used to discuss possible consequences of the introduction of ITES.

\section{Results}

\subsection{Survey}

Table 1 shows the main characteristics of the fleets per region, comparing official data (Mipaaf and NISEA, 2014) and key stakeholders' opinions. No significant differences have been found in the daily fuel costs. Considering how stakeholders were chosen (i.e. representative key agent), the number of interviews (i.e. low compared to population of fishers), and the typology 
278 of questions (i.e. oriented to get information about standard vessels rather 279 than specific vessels), the results of the survey must be evaluated in a 280 qualitative (or semi-quantitative) way rather than in a pure quantitative (i.e. 281 statistical) way. This means that relationships are validated through 282 consultation with a set of experts (i.e. focus group) rather than statistical 283 tests.

Table 1. Daily revenues, daily fuel costs and fishing days/year per region (A: Adriatic; T: Tyrrhenian) and fishery (BT: bottom trawling; PT: pelagic trawling) of average vessels and smaller/larger vessels (i.e. GT $-20 \%$ and $+20 \%$ compared to average vessels). For daily revenue and fishing days, in brackets, official data (Mipaaf, Nisea, 2014); out of brackets, figures declared by stakeholders (all declared figures are the arithmetic mean of stakeholders' answers).

\begin{tabular}{|c|c|c|c|c|c|c|c|c|}
\hline \multirow[t]{2}{*}{ Region } & \multirow[t]{2}{*}{ Fishery } & \multirow{2}{*}{$\begin{array}{c}\text { GT average } \\
\text { vessel } \\
\text { (tons) }\end{array}$} & \multicolumn{2}{|c|}{ Daily revenue } & \multicolumn{2}{|c|}{ Daily fuel cost } & \multicolumn{2}{|c|}{ Fishing days / year } \\
\hline & & & $\begin{array}{c}\text { Average } \\
\text { vessel }(€)\end{array}$ & $\begin{array}{c}\text { Capacity } \\
-20 \% ;+20 \%\end{array}$ & $\begin{array}{c}\text { Average } \\
\text { vessel }(€)\end{array}$ & $\begin{array}{c}\text { Capacity } \\
-20 \% ;+20 \%\end{array}$ & $\begin{array}{c}\text { Average } \\
\text { vessel (days) }\end{array}$ & $\begin{array}{c}\text { Capacity } \\
-20 \% ;+20 \%\end{array}$ \\
\hline Abruzzo (A) & BT & 59 & $1265(1265)$ & $-20 \% ;+20 \%$ & 694 & $-17 \% ;+17 \%$ & $120(152)$ & $-13 \% ;+10 \%$ \\
\hline Campania (T) & BT & 34 & $893(893)$ & $-20 \% ;+10 \%$ & 265 & $-23 \% ;+13 \%$ & 169 (169) & $-13 \% ;+13 \%$ \\
\hline $\begin{array}{l}\text { Emilia- } \\
\text { Romagna (A) }\end{array}$ & BT & 24 & $1210(1415)$ & $-23 \% ;+10 \%$ & 476 & $-5 \% ;+5 \%$ & $110(83)$ & $-10 \% ;+7 \%$ \\
\hline Lazio $(\mathrm{T})$ & BT & 50 & $1291(1321)$ & $-15 \% ;+5 \%$ & 544 & $-10 \% ;+5 \%$ & 167.5 (199) & $-5 \% ;+3 \%$ \\
\hline Marche (A) & BT & 57 & $1658(1787)$ & $-13 \% ;+3 \%$ & 750 & $-10 \% ;+13 \%$ & 139 (139) & $-7 \% ;+7 \%$ \\
\hline Apulia (A) & BT & 25 & $1007(1220)$ & $-17 \% ;+17 \%$ & 435 & $-13 \% ;+17 \%$ & $200(128)$ & $0 \% ; 0 \%$ \\
\hline Tuscany $(\mathrm{T})$ & BT & 31 & $1225(1256)$ & $-10 \% ; 0 \%$ & 499 & $0 \% ; 0 \%$ & $174(153)$ & $0 \% ; 0 \%$ \\
\hline Veneto $(A)$ & BT & 40 & $867(1966)$ & $-10 \% ;+25 \%$ & 410 & $-10 \% ;+10 \%$ & $112(107)$ & $0 \%, 0 \%$ \\
\hline $\begin{array}{l}\text { Emilia- } \\
\text { Romagna (A) }\end{array}$ & PT & 62 & $2435(2435)$ & $-5 \% ;+10 \%$ & 619 & $-28 \% ;+20 \%$ & $170(126)$ & $0 \% ; 0 \%$ \\
\hline Marche (A) & PT & 107 & $1602(1602)$ & $0 \% ; 0 \%$ & 870 & $-14 \% ;+13 \%$ & $163(162)$ & $-20 \% ; 0 \%$ \\
\hline Veneto $(A)$ & PT & 68 & $2875(3188)$ & $-7 \% ;+7 \%$ & 659 & $-7 \% ;+20 \%$ & $120(126)$ & $-1 \% ;+10 \%$ \\
\hline
\end{tabular}

\subsubsection{Effects of fishing capacity}

293 Stakeholders estimated the per cent difference between the average daily 294 revenue and daily fuel cost of a vessel of average capacity (for every region 295 and fishery) and those of vessels with $20 \%$ more or less capacity compared 296 to the average vessels. The regional results are aggregated in Table 2 by sea 297 basin and fishery. Since vessels characteristics, fishers' strategies and 298 available species can differ substantially even in neighbour regions, these 299 average results should be considered with a little of caution. In general, 300 stakeholders said that both revenues and fuel costs change less than 301 proportionally with changes in vessel capacity. Furthermore, for Tyrrhenian bottom trawlers, the responses indicated that revenue is increasingly 
303 inelastic as capacity increases. In fact, daily revenue drops by $15 \%$ when

304 capacity decreases and rises by only $5 \%$ when capacity increases. This fishery

305 exhibits a similar pattern for daily fuel costs.

Table 2. Daily revenues and fuel costs of standard vessels and smaller/larger vessels (data are aggregated by fishery using the arithmetic mean of regional surveys).

\begin{tabular}{|c|c|c|c|c|}
\hline Sea basin & Fishery & Capacity $-20 \%$ & Average vessel & Capacity $+20 \%$ \\
\hline & & \multicolumn{3}{|c|}{ Daily revenue $(€)$} \\
\hline Tyrrhenian & Bottom trawling & $-15 \%$ & 1136 & $+5 \%$ \\
\hline Adriatic & Bottom trawling & $-17 \%$ & 1201 & $+15 \%$ \\
\hline \multirow[t]{2}{*}{ Adriatic } & Pelagic trawling & $-4 \%$ & 2304 & $+6 \%$ \\
\hline & & \multicolumn{3}{|c|}{ Daily fuel cost $(€)$} \\
\hline Tyrrhenian & Bottom trawling & $-11 \%$ & 436 & $+6 \%$ \\
\hline Adriatic & Bottom trawling & $-11 \%$ & 553 & $+12 \%$ \\
\hline Adriatic & Pelagic trawling & $-16 \%$ & 716 & $+18 \%$ \\
\hline
\end{tabular}

For Adriatic fisheries, on the contrary, the decreasing returns to capacity seem to be constant. For pelagic trawlers, revenues seem to be much more inelastic than fuel costs. This result may be due in part to the technical specificities of this fishery and certainly is due in part to the self-management habits of some cooperatives (especially in the Marche region), where voluntary daily quotas are established for all members independent of the size of the vessels.

The relationships between capacity and daily fuel costs are difficult to analyse because, depending on the region, larger vessels may fish for more hours than smaller vessels, with a direct effect on fuel costs.

In Figure 2, revenue and fuel cost data (i.e. stakeholders' opinion) for all regional bottom trawling fleets (both Adriatic and Tyrrhenian) are shown. These data include the eight regional average vessels and the corresponding higher $(+20 \%)$ and lower $(-20 \%)$ capacity vessels (GT is indicated in the figure). From this figure, large vessels seem to have a very slight advantage compared to small vessels since the distance between daily costs and daily revenues increases with capacity.

327 The effect of fishing capacity on fishing activity is very low (i.e. fishing activity 328 is inelastic) (Table 3). This finding is the same if we consider both fishing days 
329 per year and fishing hours per day. Stakeholders in some regions (Apulia, 330 Tuscany, and Veneto) say that capacity has no effect at all on the number of 331 fishing days of bottom trawlers. Differences between regions, linked to 332 differences in the natural environment and in social habits, are much more 333 significant than differences between vessel sizes within regions. The average 334 number of fishing days varies from 110 (bottom trawling in Emilia Romagna) 335 to 200 (bottom trawling in Apulia). The average number of fishing hours 336 varies from 11 (pelagic trawling in Veneto) to more than 20 (bottom trawling 337 in Marche and Abruzzi).

Table 3. Fishing days and fishing hours of standard vessels and smaller/larger vessels (data are aggregated by fishery using the arithmetic mean of regional surveys).

\begin{tabular}{llccc}
\hline Sea basin & Fishery & Capacity $-20 \%$ & Average vessel & Capacity $+20 \%$ \\
\hline \multirow{2}{*}{ Tyrrhenian } & & & Fishing days / year & \\
Adriatic & Bottom trawling & $-6 \%$ & 170 & $+5 \%$ \\
Adriatic & Bottom trawling & $-6 \%$ & 136 & $+5 \%$ \\
\hline & Pelagic trawling & $-9 \%$ & 158 & $+2 \%$ \\
Tyrrhenian & & & Fishing hours / day & $3 \%$ \\
Adriatic & Bottom trawling & $-5 \%$ & 14.6 & $1 \%$ \\
Adriatic & Bottom trawling & $-1 \%$ & 17.9 & $6 \%$ \\
\hline
\end{tabular}

341

342

343

344

345

346

347

348

349

350

351

352

353

354

\subsubsection{Effects of fishing activity}

For most of the stakeholders, the first factor limiting the number of fishing days is weather conditions. Other reasons vary depending on the sea basin and fishery. In the case of pelagic trawling in the northern Adriatic (Veneto and Emilia Romagna), vessels remain inside the port if demand and prices are low. For Adriatic bottom trawling, stock seasonality and vessel maintenance periods are equally important in determining fishing days.

In the Adriatic Sea, the application of the 2014 Ministerial Decree has not been uniform. Depending on the geographic area, fishers have preferred to either fish five days per week for a maximum of 72 weekly hours or to fish only four days per week. The 'four days' option has been naturally preferred in areas, such as Marche and Abruzzi, where boats are larger and can fish for more hours. 
355 All stakeholders indicated that this new rule has caused both time at sea and 356 revenues to decrease, but the decrease in revenue of about $9 \%$ is less than 357 proportional compared to that of time (about 13\%). Adriatic fishers also said 358 that if they could fish for the same number of days but without weekly limits,

359 revenues would increase around 5\%. Finally, if a new regulation called for a $30 \%$ reduction in days at sea, Adriatic stakeholders would expect a less than proportional reduction in revenues (around 16\% for bottom trawling and $24 \%$ for pelagic trawling).

These opinions are not shared by Tyrrhenian fishers, where fishing day limits have never been applied. In fact, when they were asked the potential effects of a $20 \%$ or a $50 \%$ reduction in days at sea, they estimated a roughly proportional revenue reduction.

\subsubsection{Opinions on ITEs schemes}

Most of the Adriatic key stakeholders, in particular those in pelagic trawling, declared that they were satisfied by the introduction of the fishing time limits imposed by the 2014 Ministerial Decree. However, fishers who adopted the 72 weekly hours option would not appreciate the introduction of limits on the number of fishing days. Similarly, most of the Tyrrhenian fishers are opposed to such schemes.

In the case of the introduction of fishing day limits, Adriatic stakeholders would prefer to adopt a weekly allocation (i.e. four fishing days per week), whereas Tyrrhenian stakeholders would prefer to be free to allocate fishing days throughout the whole year (i.e. no weekly or monthly limits). Stakeholders who prefer weekly limits indicated that they would allow for easier control and management; furthermore, they would be critical to allow a more regular flow of products to the markets.

Most of the Adriatic stakeholders indicated that fishing day limits should be distributed equally to all vessels (as done by the 2014 Ministerial Decree) independent of vessel sizes or time series. On the contrary, on the Tyrrhenian side, opinions were less uniform, and half of the stakeholders expressed that 
larger vessels that currently use more fishing days would need more fishing days to recover fixed costs.

Both Adriatic and Tyrrhenian fishers think that the transferability of fishing days would not be a good idea. Fishers said that larger vessels would buy or lease fishing days from smaller vessels. Smaller vessel owners would simply earn rents. Control and management would be very difficult.

Finally, the responses were very diversified when different transferability schemes between vessels of different sizes were proposed. Key stakeholders representing Adriatic pelagic trawling said that no constraints should be imposed; this argument can be reasonable if it is true that large vessels have no sensible advantage over small vessels (i.e. if landings are rather inelastic to vessel capacity, as in some simulations shown in the appendix). Stakeholders in Adriatic bottom trawling said that transferability should be allowed within classes of vessels with similar capacities. Stakeholders in Tyrrhenian bottom trawling perceived all schemes as more or less equal, including 'no constraints', 'capacity classes', and 'effort indices' (expressed as GT*fishing days or engine power*fishing days, which permit to maintain a constant total fishing effort).

\subsection{Focus group}

The focus group permitted to validate (and discuss) the data collected in the survey. This further allowed to build, together with the fishery associations delegates, the bottom trawling model and the ITEs model that we present in the next sections.

\subsubsection{The bottom trawling model}

Starting from revenue and cost data collected through the survey (see Figure 2), a generic capacity-daily value added relationship was built for the bottom trawling fisheries of the Adriatic and Tyrrhenian Seas. It is important to highlight that for every Italian region there are specificities (linked to gear differences, distributions of main and secondary species, distance, depth of 
417 fishing areas, etc.) that make our generic model only a very rough and 418 pedagogical tool and not an instrument for developing positivistic 419 bioeconomic models. Gross value added is used as the output variable 420 instead of profit due to problems in the estimation of labour costs.

421 The model (shown in Figure 3), validated by the associations delegates, has 422 the following properties:

- The daily revenue curve fits the data shown in Figure 2 with decreasing returns to capacity (expressed in GT).

- Daily variable costs are derived from fuel costs, which represent approximately $76 \%$ of variable costs. The data shown in Figure 2 are used to estimate a linear relationship with a positive vertical intercept between variable costs and capacity.

- The daily value added is slightly increasing. Associations delegates indicated that the maximum daily profit is probably obtained by vessels of around $120 \mathrm{GT}^{5}$.

Fishery association delegates also confirmed that capacity has only a marginal effect on fishing days. Although large vessels may potentially stay at sea for more days, as they are less affected by weather conditions, market conditions represent a constraint that limits the actual number of fishing days.

\subsubsection{The ITEs model}

Since stakeholders confirm decreasing returns to fishing time (see appendix A), we built a simplified model indicating how the value added is distributed day by day, from the most rentable to the least (Figure 4), and we used this tool to discuss the consequences of ITEs schemes. The yearly value added

5

It is important to stress that in the Adriatic and Tyrrhenian seas, there are only a few vessels larger than $150 \mathrm{GT}$. This is not the case for vessels fishing in waters around Sicily. 
444 (73,400 euro) of an average bottom trawler (40 GT) is derived in Figure 3. 445 The number of days at sea is 150 , which is an average number for the 446 Tyrrhenian and Adriatic regions.

447 Now, suppose that, in order to reduce pressure on fish stocks, the number

474 Now, consider the case where there are no weekly constraints and the of fishing days has been limited by the management authority to $120(-20 \%)$. The effects on yearly revenues depend on two variables: i) the existence of weekly constraints (i.e. a maximum of four days per week) and ii) whether the distribution of more and less rentable days follow a seasonal pattern (i.e. all of the worst days of the year are found within the same week) or a weekly pattern (i.e. every week has a perfect distribution of good, average, and bad days). We have the following cases:

- Weekly constraints and seasonal patterns of rentable days: The revenue drop (19\%) is almost proportional to the drop in fishing time. In fact, fishers are not free to discard all of the worst days of the year.

- No weekly constraints and seasonal patterns of rentable days: The revenue drop is very small (4\%), since fishers may select and discard all of the worst days (Figure 4).

- Weekly patterns of rentable days: The revenue drop is always $4 \%$, regardless of weekly constraints.

Thus, weekly constraints may affect fishers' revenue much more than unconstrained limits, depending on the distribution of bad and good fishing days within the year. Seasonal patterns are driven by biological cycles (i.e. revenue decreases due to catch cycles), whereas weekly patterns can be the result of market forces (i.e. revenue decreases due to weekly price cycles). Focus group participants indicate that the truth is in the middle. On the other hand, stakeholders acknowledge that in the case of seasonal patterns (i.e. cycles of catches), only weekly constraints may have a significant effect on effective effort reduction, which should be the true objective of the management. 
476 with stakeholders. In Figure $5 \mathrm{a}$, Vessel $\mathrm{A}$ is an average bottom trawler. Vessel

477 B is more efficient than A; historically, it used the same number of fishing

478 days, but the value added obtained was $60 \%$ higher. With the introduction

479 of a 120-day limit, A and B have different marginal values added ${ }^{6}$. It is

480 possible to calculate that seven days should be sold from $A$ to $B$. However,

481 this exchange increases the effective fishing effort and catches (see appendix

482 B), which should be taken into account by the management authority.

483 In Figure $5 \mathrm{~b}$, a different situation is shown. Vessel $\mathrm{C}$ has the same value 484

485

486

487

488

489

490

491

492

493

494

495

496

497

498 In order to avoid an increase in effort due to the exchange of day quotas, effort quotas (expressed as GT*fishing days) could be used. We have said 500 that the value added of $B$ is $60 \%$ higher than that of $A$ (Figure $5 a$ ); from Figure

5013 , due to decreasing returns to input, we can see that this situation occurs if 502 the GT of $B(80)$ is double that of $A(40)$. In other words, in order to maintain 503 a constant nominal effort quota, $B$ should buy two days from $A$ in order to 504

6

Considering the marginal value added instead of the marginal profit is as if the whole crew decided to sell or buy quotas. 
505 the contrary, it is worthwhile for A to buy one day from B in order to fish two 506 days more.

507 This example showed to stakeholders how an effort quota might prevent the sale of fishing days from small vessels to large vessels. However, because of the difference between nominal effort and effective effort, this measure could still cause an increase in effective effort (i.e. two days of small vessels represent more pressure than one day of large vessels) and may artificially advantage inefficient vessels (see appendix B).

\section{Discussion and conclusions}

515 The results of the survey show that the application of the 2014 Ministerial Decree in the Adriatic Sea has made these stakeholders more open to fishing day restrictions compared to Tyrrhenian fishers. Adriatic fishers have seen positive effects in terms of cost reductions and price increases. Furthermore, they would maintain the current conditions (i.e. weekly constraints, equal limits for everybody, and no transferability), whereas Tyrrhenian fishers, if forced to limit the number of fishing days, would prefer different conditions (i.e. no weekly constraints and different limits by vessel size). The results also indicate that Adriatic stakeholders acknowledge a less than proportional drop in revenues due to a decrease in fishing time (indicating decreasing returns to fishing time). On the contrary, Tyrrhenian stakeholders suppose that the revenue decrease would be proportional to fishing time.

All of these results show how important direct experimentation, pilot projects, and information sharing are to change fishers' ideas about management schemes and how difficult it is for fishers to accept new proposals.

531 The focus group, carried out with the participation of Italian fishery associations, has permitted the building of some simple pedagogical tools based on realistic figures obtained through surveys that can be used by stakeholders, in particular managers of associations, cooperatives, and producer organizations, to better understand the functioning and possible consequences of ITEs schemes. 
537 Some of the opinions on ITEs collected in the survey were confirmed by the 538 models (e.g. small vessels could obtain rents with the introduction of ITEs), 539 whereas others were rejected (e.g. quotas proportional to historic fishing 540 days are better in order to avoid gratuitous rents for small vessels). In any 541 case, this exercise has increased stakeholders' knowledge about a 542 management scheme that offers some advantages in the case of mixed 543 fisheries. These advantages are particularly relevant in the case of bottom 544 trawling fisheries, whereas, for pelagic fisheries that focus on only two 545 species (sardine and anchovy), an ITQ scheme could also be applied 546 (Mulazzani and Malorgio, 2013).

547 In 2016, in conjunction with the realization of this study, the regulation for 548 pelagic fisheries has changed again. For the Adriatic Sea, a limit of 144 fishing 549 days (and a minimum of 70 days) has been imposed, with a maximum of 20 550 days per month. This limit is less than the amount that an average pelagic 551 Italian management authority, the management scheme seems to have shifted toward non-transferable effort quotas, which does not exclude the possibility that private interests, driven by differences in marginal profits, will transform it in a transferable effort quota scheme.

Several issues have to be considered in more depth in future analysis. Biological aspects have been completely ignored in this study. Biologists should have to identify the most suitable fishing day limits in the context of mixed fisheries, where the maximum sustainable yield cannot be achieved for every species. Difficult choices are required, balancing the needs of fishers and environment. The exchange of quotas between vessels may entail an increase in average catchability (i.e. efficiency), and, thus, further reductions in fishing days could be required over time (see appendix B). From an economic perspective, the advantages of vessels from one region over the vessels from other regions have not been considered in detail, but, in fact, the exchange of quotas between regions can affect local supply chains. Furthermore, as several stakeholders have highlighted, considering day restrictions without considering hours per day can be misleading, especially when fishing time patterns differ among regions. 


\section{Appendix A - Static model}

573 In the scientific literature, there is a lack of formal treatment of ITEs. Clark

574

575

576

577

578

579

580

581

582

583

584

585

586

587

588

589

590

591

592

593

594

595

596

597

598

599

600 (1980) builds a predictive model of fisheries management where, he says, 'quotas on catch are equivalent to quotas on fishing effort', which trivially follows from the assumed direct relationship between catch and effort, $Y_{i}=q B E_{i}$, where $B$ is the biomass of the fish stock, $q$ is the catchability coefficient, and $Y$ and $E$ are, respectively, the catches and the fishing effort of vessel $i$. However, this direct relationship between effort and catches is true only if $q$ is equal for every vessel.

Danielsson (2002) and Ulrich et al. (2002) discuss the efficiency of total allowable effort quotas (TAEs), but they do not consider the case of ITEs. However, Ulrich et al. (2002) recognize that TAEs require a model of the catchability dynamics. As Squires et al. (2016) highlight, effort is less well defined and homogeneous as an input than catch is as an output; controlling a single dimension of effort (e.g. days) leaves out unregulated dimensions that can be expanded ('capital stuffing') and technological progress ('effort creep') that can increase catch (i.e. effective effort increases). In contrast to catch rights, ITEs do not create incentives to overcome biological overfishing and to minimize costs but rather create incentives to maximize revenue (Squires et al., 2016).

For this work, we developed a model that takes into consideration differences between single vessels (Andersen et al., 2010; Clark, 1980). For every vessel, we consider the following Cobb-Douglas production function

$$
Y=m S^{a} D^{b} B^{g}
$$

where $Y$ is yearly catches; $S$ is a measure of fishing capacity (e.g. GT or engine power); $D$ is a measure of fishing activity (such as days at sea); $B$ is the biomass of fish stocks; $m$ is a technological parameter; and $a, b$, and $g$ are other parameters that make the function non-linear, indicating increasing or 
601 decreasing returns to inputs. Decreasing returns to inputs should be 602 expected for $S$ and $D$, even though the fishery literature includes empirical 603 estimations where the elasticity is greater than one, indicating some sort of 604 economies of scale (Bjorndal and Conrad, 1987; Eide et al., 1998).

605

606

607

608

609

610

611

612

613

614

615

616

617

618

619

620

621

622

623

624

625

626

627

628

Profit is given by

$$
\pi=p\left(m S^{a} D^{b} B^{g}\right)-\left(s S^{t}+x S^{y} D\right)
$$

where $p$ is the price of fish, $s S^{t}$ are fixed costs, and $x S^{y} D$ are variable costs. Both fixed costs and variable costs are functions of the fishing capacity $S$.

We stress that, all other coefficients constant, the effect on profit of increasing capacity $S$ depends on the values of $a, t$, and $y$. In fact, if $a>y$ and $a>t$, profit increases with $S$, and profit decreases otherwise. However, this result is certain only for infinitely high values of $S$; for values of $S$ closer to reality, profits can increase also if $a$ is lower than $y$ and $t$.

In the short term, profit depends only on days at sea $D$ (we suppose there is no difference in the length of a fishing day). Let us assume that $b<1$, meaning that there are decreasing returns to fishing days. This assumption simply means that fishers always choose more rather than less suitable days for fishing. Vessel owners will decide to fish the number of days that maximize profit. Thus, from Equation A.2, we obtain that fishing days will be

$$
D=\left(\frac{x S^{y}}{p q S^{a} B^{g} b}\right)^{\frac{1}{b-1}}
$$

From this equation, it is possible to see if vessels of larger capacity $S$ will tend to be active for more days or not. In fact, if $a>y, D$ increases with $S$; if $a<y, D$ decreases; and, finally, if $a=y, S$ has no effect and all vessels choose the same number of days at sea.

We can see in Figure A.1 some simulations of profit given different days at sea and different parameters $a, y$, and $t$. 


\section{Appendix B - Long term equilibrium model}

631 The previous model is static and can represent the behaviour of vessels in the short term. In the long term, it is necessary to consider the dynamics of the fish stocks. In this section, we assume a simple logistic growth function, which permits us to calculate steady maximum sustainable yield (MSY), maximum economic yield (MEY), and bioeconomic equilibrium (BE). Given Equation A.3, changes in the sizes of stocks directly affect the number of days at sea chosen by fishers in order to maximize their profit (i.e. lower biomass implicates fewer days at sea). MSY, MEY, and BE are functions of the number $(n)$ of vessels in the fishery and the capacity $(S)$ of each vessel. Given $n$ and $S$ for each vessel, MSY or MEY can be obtained through management imposing 641 a maximum number of days at sea $(D)$ per vessel, since $D$ chosen by single 642 fishers to maximize their short-term profits cannot guarantee these yield 643 levels.

644 For simplicity, we have simulated a situation where there are $n / 2=60$ large 645 vessels $(S=300)$ and $n / 2=60$ small vessels $(S=60)$ (Figure B.1). As expressed in 646 the questionnaire to fishers, the management authority can choose between 647 two options. It can decide to either establish equal fishing day limits for all 648 vessels, or it can establish a fishing day limit that is proportional to the 649 historic days at sea of each vessel. For example, if we consider the case 650 shown in Figure A.1a as historical information, large vessels used to work 296 651 days per year and small vessels 198 days per year, and, thus, the restriction 652 should be applied proportionally. In Figure B.1a, steady profits ${ }^{7}$ (i.e. at 653 equilibrium) are shown for small and large vessels for different levels of TAE. 654 The total profit of the fleet as a whole does not change considerably across 655 the two management strategies, but the distribution of the benefits between the two groups of vessels is very different. Large vessels, in particular, are negatively affected by equal fishing day limits.

7

Steady solutions have been calculated simulating the dynamics of the fish stock for a $60-$ year period until the equilibrium is obtained. 
658 The situation can change further if fishing days are transferable between 659 vessels in an ITEs scheme. The exchange should happen when vessel owners 660 have different marginal profits for the last fishing day they are allowed to 661 use. With this management scheme, given a certain total number of fishing 662 days for the fleet, the final distribution of fishing days between small and 663 large vessels is not affected by the initial allocation of limits (i.e. equal for all 664 or proportional to historical fishing days) since the exchange of quotas 665 continues until all of the vessels have the same marginal profit. However, a 666 higher concession of fishing days at the moment of the initial allocation can 667 be converted into rents when the quota exchange occurs. In a situation as 668 669

Given a certain TAE, the total catches and profits of the fleet change if the distribution of days between vessels is determined by fixed (i.e. equal for all vessels) quotas, proportional quotas, or transferable quotas. Fixed quotas entail the lowest average catchability for the fleet, which means low shortterm efficiency. On the contrary, transferability permits the highest catchability or short-term efficiency for the fleet. However, this high efficiency also entails high exploitation of the fish stock, which affects the long-term potential of the fishery. In other words, in equilibrium (as shown in Figure B.1b), a transferable fishing days scheme can obtain the same catches or profits of a fixed days scheme only through a further reduction of 680

To avoid an increase in fishing mortality, a different approach is a management scheme that explicitly considers capacity to maintain a constant total effort of the fleet. Here, the choice is between an index of nominal effort and an index of effective effort (Figure B.2).

In the first case, capacity*fishing day $\left(S^{*} D\right)$ could be easily applied and understood by fishers and authorities. The problem is that the nominal effort cannot perfectly reflect the ability of vessels to catch fish (i.e. effective effort or fishing mortality). In other words, assuming decreasing returns to capacity (i.e. $a<1$ ), a vessel $A$ that is five times larger than a vessel $B$ catches less than five times the catches of $B$. In this situation, also considering a relationship 
691 between variable costs and capacity that is favourable to large vessels (such

692 as in Figure A.1a, where $a>y$ ), small vessels may have higher marginal profits

693 than large vessels for the last unit of nominal effort $\left(S^{*} D\right)$ that they are 694 allowed to use.

695 Thus, ITEs based on indices of nominal effort may affect the long-term 696 efficiency of the fishery as much or more than those based on transferable 697 fishing days since less efficient vessels (the small ones) are artificially 698 advantaged by the ITE scheme, leading to an increase in effective effort.

699 ITEs based on indices of effective effort, on the contrary, are the only 700 schemes where the average catchability of the fleet does not change due to 701 the exchange of quotas between vessels of different sizes (i.e. in the short702 term, the total catches of the fleet do not change). In this way, vessels that 703 are truly efficient, those that have the lowest marginal cost per unit of catch, 704 or those that get the best prices (e.g. improving fish quality) can emerge and 705

706

707

708

709

710

711

712

713

714

715

716

717

718

719

720

721 buy effort quotas (Figure B.2).

The potential advantage of effective effort quotas, however, increases in the very long-term when, beyond the exchange (or leasing) of days at sea (i.e. activity) weighed in effort quota terms, firms may decide to exchange capacity, also weighted in effort quota terms. In other words (assuming parameters as in Figure A.1a), small vessels are retired and replaced by a smaller number of large vessels. In fact, assuming different efficiencies of vessels (i.e. different cost per unit of catch), less efficient vessels should, theoretically, be completely substituted by more efficient ones. This substitution would permit greater profits for the fleet at both the MSY and the MEY level.

\section{Funding sources}

This work was supported by the Italian Ministry of Agricultural, Food and Forestry Policies (grant number CUP J88C13001270001). 


\section{References}

Andersen, P., Andersen, J.L., Frost, H., 2010. ITQs in Denmark and Resource Rent Gains. Mar. Resour. Econ. 25, 11-22. doi:10.5950/0738-136025.1.11

Baudron, A., Ulrich, C., Nielsen, J.R., Boje, J., 2010. Comparative evaluation of a mixed-fisheries effort-management system based on the Faroe Islands example. ICES J. Mar. Sci. 67, 1036-1050. doi:10.1093/icesjms/fsp284

Bellanger, M., Macher, C., Guyader, O., 2016. A new approach to determine the distributional effects of quota management in fisheries. Fish. Res. 181, 116-126. doi:10.1016/j.fishres.2016.04.002

Bjorndal, T., Conrad, J.M., 1987. The dynamics of an open access fishery. Can. J. Econ. 20, 74-85.

Breen, P.A., Branson, A.R., Bentley, N., Haist, V., Lawson, M., Starr, P.J., Sykes, D.R., Webber, D.N., 2016. Stakeholder management of the New Zealand red rock lobster (Jasus edwardsii) fishery. Fish. Res. 183, 530538. doi:10.1016/j.fishres.2015.12.004

Christy, F.T.J., 1973. Fisherman quotas: a tentative suggestion for domestic management. (No. 19), Occasional paper series. Kingston.

Clark, C.W., 1980. Towards a Predictive Model for the Economic Regulation of Commercial Fisheries. Can. J. Fish. Aquat. Sci. 37, 1111-1129. doi:10.1139/f80-144

Cleland, D., 2017. A playful shift: Field-based experimental games offer insight into capacity reduction in small-scale fisheries. Ocean Coast. Manage. 144, 129-137. doi:10.1016/j.ocecoaman.2017.05.001

Danielsson, A., 2002. Efficiency of catch and effort quotas in the presence of risk. J. Environ. Econ. Manage. 43, 20-33. doi:10.1006/jeem.2000.1168

Eide, A., Skjold, F., Olsen, F., Flaaten, O., 1998. Production Functions of the Norwegian bottom trawl fisheries of cod in the Barents Sea, in: Proceedings of the IXth International Conference of the International Institute for Fisheries Economics and Trade. Norwegian College of Fishery Science, Tromso, pp. 357-362. 
755

756

757

758

759

760

761

762

763

764

765

766

767

768

769

770

771

772

773

774

775

776

777

778

779

780

781

782

783

784

785

786

787

Glaser, M., Breckwoldt, A., Deswandi, R., Radjawali, I., Baitoningsih, W., Ferse, S.C.A. 2015. Of exploited reefs and fishers - A holistic view on participatory coastal and marine management in an Indonesian archipelago. Ocean Coast. Manage. 116, 193-213. doi:10.1016/j.ocecoaman.2015.07.022

González Laxe, F., 2006. Transferability of fishing rights: The Spanish case. Mar. Policy 30, 379-388. doi:10.1016/j.marpol.2005.06.008

Jákupsstovu, S.H.Í., Cruz, L.R., Maguire, J.J., Reinert, J., 2007. Effort regulation of the demersal fisheries at the Faroe Islands: A 10-year appraisal. ICES J. Mar. Sci. 64, 730-737. doi:10.1093/icesjms/fsm057

Lucchetti, A., Piccinetti, C., Meconi, U., Frittelloni, C., Marchesan, M., Palladino, S., Virgili, M., 2014. Transferable Fishing Concessions (TFC): A pilot study on the applicability in the Mediterranean Sea. Mar. Policy 44, 438-447. doi:10.1016/j.marpol.2013.10.009

Manrique de Lara, D.R., Corral, S. 2017. Local community-based approach for sustainable management of artisanal fisheries on small islands. Ocean Coast. Manage. 142, 150-162. doi:10.1016/j.ocecoaman.2017.03.031

Martin-Smith, K.M., Samoilys, M.A., Meeuwig, J.J., Vincenta, A.C.J. 2004. Collaborative development of management options for an artisanal fishery for seahorses in the central Philippines. Ocean Coast. Manage. 47, 165-193. doi:10.1016/j.ocecoaman.2004.02.002

Mipaaf, NISEA, 2014. Programma Nazionale raccolta dati alieutici.

MRAG, IFM, CEFAS, AZTI Tecnalia, PolEM, 2009. An analysis of existing Rights Based Management (RBM) instruments in Member States and on setting up best practices in the EU, Final Report FISH/2007/03. London.

Mulazzani, L., Malorgio, G., 2013. Regional management of multi-species fisheries on the basis of shared stocks and property rights: A Mediterranean case | Gestión regional de pesquerías multiespecíficas basada en stocks compartidos y derechos de propiedad: un caso Mediterráneo. Sci. Mar. 77. doi:10.3989/scimar.03693.05B

OECD, 2006. Using market mechanisms to manage fisheries. Smoothing the 
path. OECD Publishing, Paris. doi:10.1787/9789264036581-en

789

790

791

792

793

794

795

796

797

798

799

800

801

802

803

804

805

806

807

808

809

810

811

812

Pido, M. 1995. The application of rapid rural appraisal techniques in coastal resources planning: experience in Malampaya Sound, Philippines.

Ocean Coast. Manage. 26, 57-72.

Silver, J.J., Campbell, L.M., 2005. Fisher participation in research: Dilemmas with the use of fisher knowledge. Ocean Coast. Manage. 48, 721-741. doi:10.1016/j.ocecoaman.2005.06.003

Squires, D., Maunder, M., Allen, R., Andersen, P., Astorkiza, K., Butterworth, D., Caballero, G., Clarke, R., Ellefsen, H., Guillotreau, P., Hampton, J., Hannesson, R., Havice, E., Helvey, M., Herrick, S., Hoydal, K., Maharaj, V., Metzner, R., Mosqueira, I., Parma, A., Prieto-Bowen, I., Restrepo, V., Sidique, S.F., Steinsham, S.I., Thunberg, E., del Valle, I., Vestergaard, N., 2016. Effort rights-based management. Fish Fish. 1-26. doi:10.1111/faf.12185

Squires, D., Maunder, M., Vestergaard, N., Restrepo, V., Metzner, R., Herrick, S., Hannesson, R., del Valle, I., Andersen, P., 2012. Effort rights in fisheries management, FAO Fisheries and Aquaculture Proceedings.

Trimble, M., de Araujo, L.G., Seixas, C.S. 2014. One party does not tango! Fishers' non-participation as a barrier to co-management in Paraty, Brazil. Ocean Coast. Manage. 92, 9-18. doi:10.1016/j.ocecoaman.2014.02.004

Ulrich, C., Pascoe, S., Sparre, P.J., Wilde, J.-W. De, Marchal, P., 2002. Influence of trends in fishing power on bioeconomics in the North Sea flatfish fishery regulated by catches or by effort quotas. Can. J. Fish. Aquat. Sci. 59, 829-843. doi:10.1139/f02-057 